\title{
Influence of process variables on the kinetic parameters of a Langmuir-Hinshelwood expression for E.coli inactivation during the photocatalytic disinfection of water
}

Andrea L. Moreno-Ríos, Luz M. Ballesteros \& Camilo A. Castro-López

DOI: http://doi.org/10.1080/01496395.2019.1676784

\begin{abstract}
This research describes the effect of the photocatalyst concentration, irradiation power, concentration of inorganic salts and the initial $\mathrm{pH}$ on the three parameters of a LangmuirHinshelwood-model: inactivation kinetic constant; $k$, dimensionless interaction coefficient; $\mathrm{K}^{*}$, and inhibition coefficient; $n$, which was applied to the photocatalytic disinfection of water with TiO2. In general, there is a qualitative finding in the effects on parameters of some variables since an increase in $\mathrm{k}$ was always related to a decrease in $\mathrm{K}^{*}$. Such relation was observed for the amount of $\mathrm{TiO} 2$, the irradiation power and the increase in concentration of inorganic salts: $\mathrm{NaCl}$ and $\mathrm{CaCO}$. Moreover, increase in $\mathrm{MgSO} 4$ concentration do not cause a tendency of change on the described parameters. As for $\mathrm{pH}$ of the reaction media, an increasing effect on $\mathrm{k}$ is observed when its value promotes proximity between bacteria and $\mathrm{TiO} 2$ particles. Finally, small changes were observed for $\mathrm{n}$ with the studied variables, but indeed significant for mathematical fitting. Thus, these findings led to the formulation of a mathematical description of the effects of the most important variables and their interactions on the kinetic parameters. This last hypothesis was validated by comparison of experimental and predicted data with high correlations.
\end{abstract}

Keywords: Photocatalytic disinfection, TiO2 , kinetics, process variables 